\title{
Effects of herding behavior of tradable green certificate market players on market efficiency: insights from heterogeneous agent model
}

\author{
(C) Higher Education Press 2021
}

\begin{abstract}
Tradable green certificate (TGC) scheme promotes the development of renewable energy industry which currently has a dual effect on economy and environment. TGC market efficiency is reflected in stimulating renewable energy investment, but may be reduced by the herding behavior of market players. This paper proposes and simulates an artificial TGC market model which contains heterogeneous agents, communication structure, and regulatory rules to explore the characteristics of herding behavior and its effects on market efficiency. The results show that the evolution of herding behavior reduces information asymmetry and improves market efficiency, especially when the borrowing is allowed. In addition, the fundamental strategy is diffused by herding evolution, but TGC market efficiency may be remarkably reduced by herding with borrowing mechanism. Moreover, the herding behavior may evolve to an equilibrium where the revenue of market players is comparable, thus the fairness in TGC market is improved.
\end{abstract}

Keywords tradable green certificate, herding behavior, evolution, heterogeneous agent model, complex network

\section{Introduction}

The International Energy Agency (IEA) pointed out that in 2019, global energy-related carbon emissions flattened in 2019 at around 33 giga tonnes (Gt), following two years of increase [1]. However, the United Nations Environment

Received Oct. 19, 2020; accepted Jan. 19, 2021; online Jul. 10, 2021

Yi ZUO, Xingang ZHAO ( $\bowtie)$

School of Economics and Management, North China Electric Power University, Beijing 102206, China; Beijing Key Laboratory of New Energy and Low-Carbon Development, North China Electric Power University, Beijing 102206, China

E-mail: rainman319@sina.com
Programme estimates that global greenhouse gas emissions must be reduced by $7.6 \%$ per year between 2020 and 2030 in order to control the warming within $1.5^{\circ} \mathrm{C}$ [2]. As energy industry is the largest source of greenhouse gas emissions, the renewable energy industry should be developed to replace fossil energy and accelerate energy transformation. In addition, the COVID-19 pandemic has struck the global economy, and countries have announced economic recovery plans to stabilize expectations, restore confidence, and guide savings into productive investment. One way to rebuild confidence is to guide the investment flow, which cannot only drive growth but also balance sustainable investment organization of physical capital, human capital, social capital, intangible capital and natural capital [3]. The renewable energy industry can create more jobs in the short-term, further stimulate consumption, and expand demand. In the long run, the advantage of renewable energy (RE) fixed assets investment is that it requires less labor for operation and maintenance [4], which helps to liberate productivity while restoring economic. It can be seen that RE investment has dual benefits of economy and environment. To promote the development of the RE industry, many countries have introduced tradable green certificate (TGC) scheme, such as United States, the UK, the Netherlands, Sweden, and Norway.

The TGC scheme uses market-oriented means to provide RE manufacturers with additional benefits besides the revenue from physical electricity. On the one hand, it can encourage RE investment to promote the growth of RE installed capacity, and on the other hand, it introduces a competitive mechanism to impel manufacturers to reduce production costs through the technological progress. The TGC scheme is both an accounting system that certifies RE production and a regulatory instrument available for public authorities to reach a specified goal for RE production. The market for TGC consists of supply and demand for certificates in which the supply of certificates is ensured by 
the producers of $\mathrm{RE}$ for each unit of $\mathrm{RE}$ sold to the grid, while the demand is driven by a politically determined quota for RE consumption. Some reports show that more than half of the RE generation is derived from the introduction of the TGC system in United States [5].

The TGC market efficiency represents the degree of the information reaction of TGC price, which means whether the price can truly reflect the production cost of RE, the changes in supply and demand side, and market risks, $[6,7]$. However, empirical studies show that the herding behavior which widely exists in financial market has interactions with asset prices and may reduce market efficiency, especially in emerging market because of weaker supervision and information disclosure [8-10]. In recent years, many countries, such as China and India, have begun to establish the TGC market. In the emerging TGC market, market players with limited rationality may imitate decisions of others, then homogeneous decisionmaking behaviors may cause excessive disturbance to TGC price, thereby reducing market efficiency [11]. Some scholars have studied the herding behavior in similar energy derivatives markets, and found the correlation between herding behavior and asset prices. In the European Carbon Futures Market, the herding behavior and carbon price volatility also interact with each other [12]. In the crude oil futures market of the United States, the herding among speculative traders is negatively correlated with contemporaneous volatility and does not lead to the next-day volatility [13]. Researches show that the herding behavior stems from the heterogeneity among players, such as information asymmetry and strategy preference $[14,15]$. Heterogeneity causes differences in decision-making, which, in turn, leads to the revenue gap. The evolution of herding behavior is a strategy evolutionary process that market players with active selfadaptation ability interact with the surroundings constantly, accumulate experience, and adjust behavior accordingly. In view of the strong correlation between the herding behavior and the market efficiency in the TGC market, it is necessary to clarify the impact of the herding behavior on market efficiency, especially for the effective operation of the emerging TGC market.

TGC, as a power derivative, is a financial asset, thus the TGC market can be regarded as a financial market and it is possible to study the strategic behaviors based on the relevant financial theories [16]. In this paper, an artificial TGC market model (ASM-TGC) is proposed based on the artificial stock market (ASM) model to simulate TGC transaction considering herding behavior. In the model proposed, the indicator of the influence of the herding behavior on market efficiency is the extent of price deviation from value $(D V)$ and price volatility $(V P)$. Information asymmetry and strategy preference are triggers of the herding behavior, and the dynamic scalefree network represents the relationship structure among agents. The simulation is to explain the mechanism of the effect of herding behavior on the TGC market efficiency. Based on the results, the impacts of regulatory rules (banking, borrowing, and penalty) on herding evolution are discussed.

This paper is innovative because most of the existing literature on TGC trading ignores adaptive behaviors of market players, but this paper considers the limited rationality and heterogeneity of the player and concentrates on imitation among players. In addition, the heterogeneous agent model is applied to simulate TGC market, it contains multiple agents' dynamic decision making processes and several regulatory rules, which enables market players and regulators to determine the possible consequences of different decisions and policies in both the preliminary design and operating phases of TGC and other energy market. Moreover, the effects of herding behavior on TGC market efficiency are discussed, and based on the mechanism, regulatory rules of banking, borrowing and penalty are also discussed. The proposed simulation instrument can well assist both the regulators in choosing appropriate policies, and the market players in testing the efficiency of trading strategies, in the initial design stage or in the operating phase of TGC and other energy market.

This paper first reviews the relevant literature. It then explains agent heterogeneity, complex network and herding evolution. After that, it gives the methodology needed for the research and analyzes the impacts of herding evolution on TGC market efficiency. Finally, it discusses the impacts of regulatory rules and puts forward relevant suggestions.

\section{Literature review}

\subsection{Strategic behavior in TGC market}

Studies on the strategic behavior of the TGC market players mainly focus on the optimal trading strategies and their influences on the market. Ghaffari et al. figured out the equilibrium strategies in different game models and analyzed their effects on players' revenue, electricity price, and power generation [17]. Hasani-Marzooni and Hosseini studied the combination of value trading strategies and trend following strategies to maximize the returns of agents and evaluate the effectiveness of market design [18]. Yi et al. examined electricity producers' strategies under the background of evolution from feed-in tariff (FIT) to renewable portfolio standards (RPS) scheme and studied the impacts of scheme parameters (subsidy, quota, and penalty) on TGC market operation [19]. Vogstad et al. discovered that the instabilities of TGC market arose endogenously from the trading strategies, but some regulatory rules such as banking and borrowing could reduce it [20]. An et al. explored the behaviors of market 
players in TGC market and their impacts on TGC price [21].

The above studies are mainly focused on the effects of market mechanisms or market parameters based on strategic behavior simulations. The limitations on the characterization of agents' strategic behavior are that the bounded rationality of agents and the interaction among them are not taken into account. According to the behavioral finance theory, as market participants are affected by personal preferences, cognitive abilities and psychological factors, their strategic behavior is bounded rational with significant individual diversity. Differences exist in the benefits of subjects because the subjects' decision-making are affected by the information provided by the external environment and their own cognition of information. To improve performance, the subjects may learn the strategies of others through communication. Thus, this paper focuses on the interaction among agents and explores the characteristics of herding behaviors.

\subsection{Impacts of herding behavior on asset price}

The influence of herding behavior on the market is mainly concentrated on price volatility and price deviation from value. In the study of price volatility, some scholars claim that herding behavior exacerbates asset price fluctuation. Maug and Naik observed that if institutional investors buy or sell the same stock at the same time, the pressure of buying or selling will exceed the liquidity that the market can provide, resulting in discontinuities and large changes in the stock price [22]. Empirical results of Huang et al. found that the herding behavior in the equity market shows distinct patterns under various portfolios according to idiosyncratic volatility [23]. Yamamoto discovered that the relationship between the information sharing degree of herding behavior and agglomeration of asset price fluctuations is monotonic [24].

However, some scholars also argue that herding behavior is conducive to market stability as it promotes the return to equilibrium price. Lakonishok et al. pointed out that the herding behavior of institutional investors and the irrational behavior of individual's investors have a countervailing effect, which promotes the stock price to equilibrium value [25]. The research of Wermers illustrated that strongly bought stocks by the fund will have higher returns in the next six months, indicating that the herding behavior of buying stocks accelerates the process of integrating new information into price [26]. Choi and Skiba hold that herding is a mechanism through which fundamental information is incorporated into security price. Therefore, it seems that price stabilizing and price adjustment toward fundamental values is faster in more transparent markets [27]. The simulation of Hessary and Hadzikadic revealed that a significant bidirectional causal relationship is detected between herding and volatility in the market [28].
In terms of price deviation from fundamental value, scholars also hold different opinions. Lux explained that the emergence of bubbles is a self-organizing process of infection among traders and leads to equilibrium price which deviates from the fundamental value [29]. Kaizoji stated that the mutual imitation of speculative behavior leads to the generation, expansion, and collapse of bubbles [30]. Foroni and Agliari noted that when the contagious effect of the market exceeds a critical value, the market price cannot converge to value [31]. In contrary, experiment directed by Manahov and Hudson indicated that the market price moves back to the fundamental value and that there is no tendency toward price crashes or bubbles [32].

The above literature review indicates that the impact of herd behavior on asset prices is uncertain. To clarify the impact of herd behavior on price in specific situations, the interaction mechanism between herd behavior and price should be studied in depth. Although the method of empirical research can verify the correlation between herd behavior and price in the market, it is difficult to explain the underlying mechanism, and the simulation method can simulate the market trading scenario, characterize the agents' herd behavior, and analyze the impact of herd behavior on the price. Therefore, this paper utilizes the agent-based model to simulate the evolution of herding behavior and study its effects.

2.3 Interaction between herding behavior and asset price based on heterogeneous agent model

Although the method of empirical research can verify the correlation between the herding behavior and price in the market, it is difficult to explain the underlying mechanism. To clarify the impact of herding behavior on price in specific situations, heterogeneous agent models (HAMs) are applied to describe herding, simulate the trend of asset price, and explain price behavior from the market microstructure perspective.

Many scholars use the HAMs to study the influence of herding behavior on asset price from the perspectives of information asymmetry and strategy preferences. The impacts of the herding behavior triggered by information asymmetry on the price is related to the uncertainty of information. An opaque information environment is conducive to lead to herding behavior [33]. Two-dimensional uncertainty (the existence and effect of value shocks) will cause herding behavior, but will not cause price to deviate from asset value. Only three-dimensional uncertainty (quality of information) can cause herding behavior and price deviation from asset value [34]. In a financial market open to the arrival of external information, the greater importance of herding with respect to the idiosyncratic tendency may play an important role in the development of instabilities [35]. Considering the reality, the fundamental information related herding behavior are 
periodic and country specific [36]. But herding behavior causes no long-run mispricing of assets, because the market is consistent with the steady flow of information, resulting in the price being orientated toward true values [32]. If information acquisition compelling herding is costly, the information externality of the second decisionmaker will influence the efficiency of the herding behavior among subsequent decision-makers [37].

In a market with multiple strategic players, mutual imitation leads to the complex and chaotic nonlinear dynamic characteristics of price formation [38]. Herding behavior will cause price fluctuations if it imitates positive feedback strategies, but it will promote price stabilization if it imitates fundamental strategies [39]. Investors adopting the negative and positive feedback strategy will offset their respective effects. Therefore, the trading behaviors of institutional investors do not result in increased volatility [40]. But when the number of chartists in the market exceeds a certain threshold, short-term fluctuations in the market will occur. As the trend strategy is not sustainable, the entity will eventually switch to a fundamental strategy [41]. Specifically, when the positive feedback strategy has a high return, the player will abandon the fundamental strategy and imitate the positive feedback strategy. This herding behavior causes the price to continue the certain trend. However, as price continues to deviate from value, the benefits of fundamental strategies will increase, and entities will, instead, imitate fundamental strategies, thereby guiding price to converge to value. The reason for this is that, with a certain dominance of chartist practices, deviations from the fundamental equilibrium become self-reinforcing and the system cannot maintain its local stability any more [42-44].

Current studies based on the HAM contribute to explanation of the effects of herding behavior on asset price, but there is generally a lack of study on the influence of internal and external factors on the evolution of herd behavior to explain the inherent evolution mechanism of herd behavior and regularity. Therefore, this paper applies HAM to explain the herding driven by information asymmetry and strategy preference.

\section{Bounded rationality based agent heterogeneity, complex network, and herding evolution}

The bounded rationality of players in TGC market is reflected in incomplete information, transaction costs, and personal preferences $[45,46]$. First, the price of TGC is affected by many factors such as macroeconomics, climate environment, RE technology progress, electricity market, and carbon market. A large amount of information changes dynamically, so relevant information on TGC is incomplete. Secondly, in terms of transaction cost, with the existence of the costs of searching for information, making decisions, and executing decisions, players can only obtain limited information. Finally, player's personal preferences and limited cognitive level act together in the decisionmaking process, and the understanding of the decisionmaking results leads to the evolution of the decisionmaking process and strengthens the constraints of bounded rationality. Different from the player's pursuit of maximum returns under the assumption of complete rationality, the player attempts to increase returns through adaptive behavior within the framework of bounded rationality closer to reality.

The heterogeneity of TGC market players drives the emergence of herding behavior. There are various types of TGC market players. As far as the TGC supply-side is concerned, with the rapid development of the RE industry, there are both large-scale RE power generation manufacturers and small-scale ones operating distributed power generation projects. In terms of power distribution companies in the demand-side, many countries have introduced competition in the power distribution and sales process in the reform of the power system. There are not only power sales companies with power generation assets, but also independent power sales companies without power generation and grid assets. Market players with multiple scales have different information and their own decision-making capabilities, leading to differences in profitability. From the perspective of decision-making, the player's heterogeneity is mainly reflected in information asymmetry and strategic preference. To reduce the cost of mining information or improve the level of decisionmaking, manufacturers may directly imitate the strategies of other players. This kind of group imitation behavior is the herding behavior.

Aggregation of interactions at the micro level generate sophisticated structure at the macro level. Many researches on complex network show that many networks in real life reflect the power-law properties of scale-free networks $[47,48]$. In the TGC market, owing to the resource advantages of some large manufacturers, market players are more willing to communicate with them and imitate their strategies. The characteristic is similar to that of scalefree networks, thus scale-free network is applied to represent the relationship network among market players. Additionally, since players may replace "neighbors" to obtain better decision information, the network evolves dynamically with herding behavior.

In the TGC market, players, for the purpose of increasing utility, comprehensively consider the historical income of themselves and others in the neighborhood, weigh the degree of imitating others' strategies, and adjust strategies. The endogenous evolutionary switching of strategies is the evolution of herding behavior which is promoted by the heterogeneity of players and the complexity of the communication structure. 


\section{Methodology}

Compared with other financial assets, TGC is a kind of quasi-financial asset. Its particularity lies in the fact that TGC trading is to achieve RPS requirements with the restriction of regulatory rules. As a result, this model has three main characteristics: the supply and demand side are different market players, the former being RE producers, and the latter, distribution companies (Discos); benchmark transaction volume is set in decision-making, since Discos must comply with their regulatory obligations in specific period; and the historical return of agents are calculated based on quota completion. Additionally, compared with general agent models, the novelty of this model is reflected in the introduction of the concept of information asymmetry and infection coefficient to represent the heterogeneity of agents and the evolution of herding behavior. The structure of this section follows the standard protocol ODD $[49,50]$.

\subsection{Purpose}

The purpose of ASM-TGC model is to understand the evolution of the herding behavior and its impacts on market efficiency.

\subsection{Process overview and scheduling}

The ASM-TGC model is an agent-based model simulating the TGC transaction between RE producers and the obligation players who are set as Discos in this paper. The rationale of the ASM-TGC model is shown in Fig. 1. According to TGC market trading rules, the supervision sector is responsible for issuing TGCs to qualified RE producers, and checking whether the TGCs delivered by
Discos can meet the quota requirement. If the quota is not satisfied, the supervision sector will impose penalty on Discos. This model assumes each unit of RE produced represents one unite TGC. Agents make decisions according to strategy preferences based on private information and neighbor information comprehensively, and then submit expected sales volume (or purchasing volume).

\subsection{State variables and scales}

Factors affecting decision-making include the environment containing dynamic returns and risks, the complex internal state of the organism, and agents' imperfect knowledge of the environment [51]. In this model, heterogeneous agents make decisions in the light of private information, personal strategy preferences, and neighbor information. Indices, parameters, and variables are shown in Table 1, their values are set after multiple debugging based on some literature and reports, explanations of some key parameters are as follows.

\subsection{Design concepts}

Emergence: Herding behavior emerges from information asymmetry and strategy preference.

Adaptation: The decision-making of agents depends both on private and neighbor information. For the purpose of maximizing revenue, agents will increase the proportion of high-revenue neighbor decision in their strategy.

Prediction: Fundamentalists predict that the price will approach value, thus they tend to invest in undervalued assets (price lower than the value). Momentum trader's estimation is consistent with the price trend in the observation period, while contrarians are opposite.

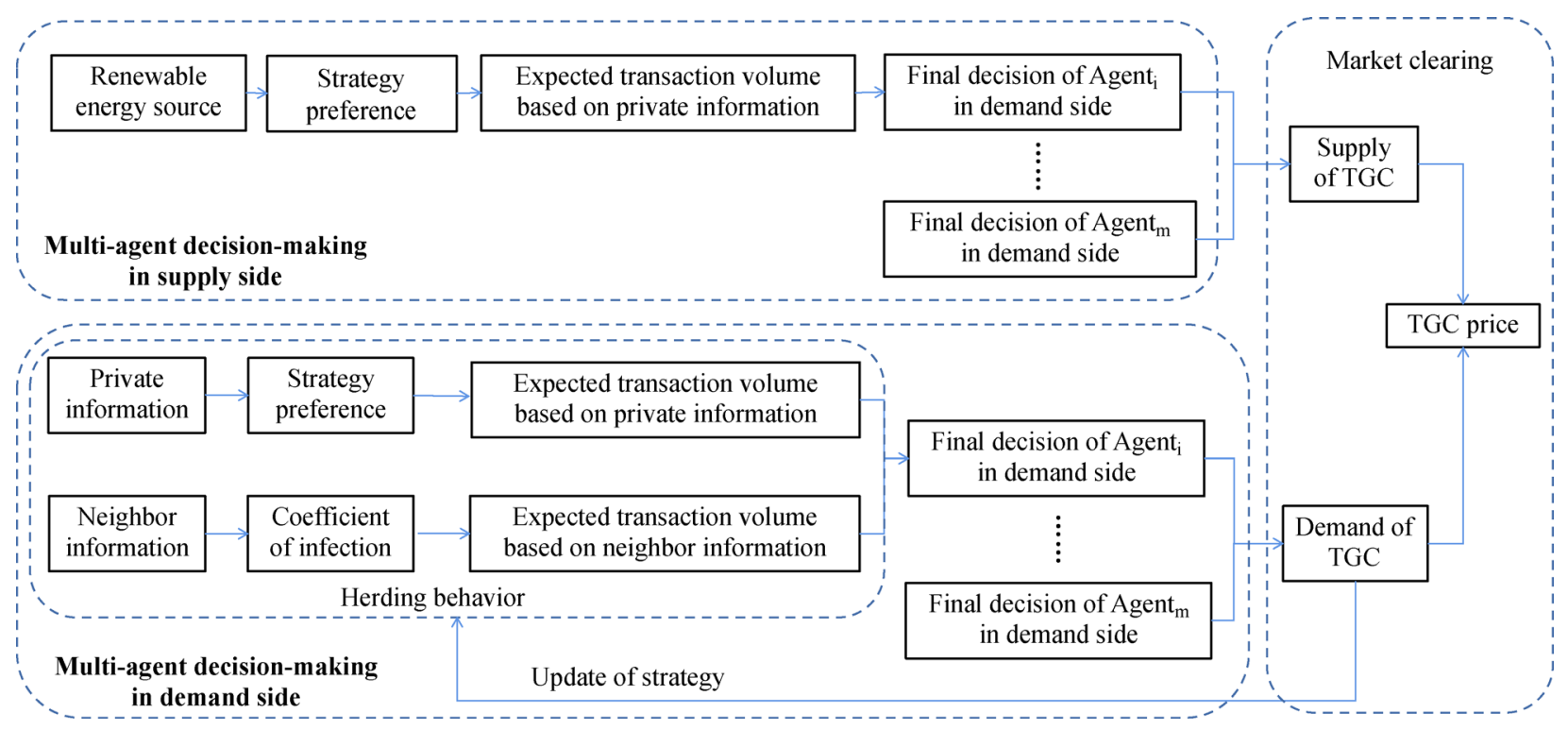

Fig. 1 Rationale of ASM-TGC model. 
Table 1 Nomenclature

\begin{tabular}{|c|c|c|}
\hline Indices, parameters, and variables & Meaning & Initial value \\
\hline$\overline{D V}$ & Price deviation from value & - \\
\hline$V P$ & Price volatility & - \\
\hline$V_{t}$ & TGC value & 0.3 \\
\hline$t$ & TGC trading period & - \\
\hline$i$ & The agent representing Disco & - \\
\hline$\overline{B_{t}^{i}}$ & Benchmark transaction volume & $1.558 \times 108$ \\
\hline$Q_{b}^{i}$ & Quota requirement of each Disco & $1.87 \times 1010$ \\
\hline$T$ & Total trading period & 120 \\
\hline$B_{j_{m}, t-1}$ & Last transaction decision of the neighbor & - \\
\hline$B_{t}^{i}, B_{\mathrm{F}, t}^{i}, B_{\mathrm{M}, t}^{i}, B_{\mathrm{C}, t}^{i}$ & $\begin{array}{l}\text { Final transaction decision of fundamentalist, momentum trader } \\
\text { or contrarian }\end{array}$ & - \\
\hline$P$ & TGC price & - \\
\hline$B o r_{i, t}$ & Number of borrowed TGCs & - \\
\hline$\alpha, \gamma$ & Sensitivity coefficient of fundamental strategy & 2 \\
\hline$\beta$ & Sensitivity coefficient of trend strategy & 3 \\
\hline$C I_{i}$ & Coefficient of infection & 0.5 \\
\hline$m p$ & Memory period & 3 \\
\hline$\mu$ & Change rate of $C I$ & 0.005 \\
\hline$m$ & Number of the neighbors & 3 \\
\hline$j_{m}$ & Neighbor of agent $i$ & - \\
\hline$a_{i, j_{m}}$ & Contribution rate of the agent's neighbor decision & - \\
\hline$N_{t}^{i}$ & Final decision of neighbors & - \\
\hline Trend & Price trends over the past period & - \\
\hline$L$ & Observation period & 3 \\
\hline$H_{t}^{i}$ & Amount of TGCs held by the agent after submitting the TGCs & - \\
\hline$\overline{S^{j}}$ & Average volume of TGC sold in each transaction & - \\
\hline$C_{t}^{i}$ & Cost of agent & - \\
\hline$f$ & Fine & 0.6 \\
\hline$\delta$ & Random coefficient of RE production & $U(-0.1,0.1)$ \\
\hline$k$ & Agent representing RE producer & - \\
\hline$S_{t}^{k}$ & Decision of RE producer & - \\
\hline$\lambda$ & Price adjustment coefficient & 1 \\
\hline$S_{t}$ & Total supply of TGCs & - \\
\hline turn $\operatorname{in}_{t}^{i}$ & Amount of TGCs submitted to regulatory authority & - \\
\hline$D_{t}$ & Total demand of TGCs & - \\
\hline$t_{-} m a$ & Moving average period & 15 \\
\hline
\end{tabular}

Notes: $C I$ : Initial value is set as 0.5 in order to reflect the subsequent changes and the comparison with different types of agents. In addition, it reveals the combination of fundamental and technical analyses. $\mu$ : The value is set as 0.005 to avoid $C I<0$ or $C I>1$. $V_{t}$ : The initial value equals long-term marginal cost difference between RE and conventional energy, as the role of TGC is to make up RE producers' cost. $\delta$ : The large fluctuation range makes the simulation results of the scenario too random, which does not reflect the difference between scenarios. Therefore, it is set as $U(-0.1,0.1)$ to simulate RE production. $\lambda$ : It represents the sentiment of agents on TGC price. $t$ ma: The moving average will be inaccurate or will not reflect the complete fluctuation if the period is too long or short. Therefore, 15 is found to be relatively appropriate after repeated comparison. 
Sensing: This model assumes that RE producers are aware of the real value of TGC $\left(V_{t}\right)$ and trade as fundamentalists. Besides, this model assumes that each agent has a certain probability $C I$ (called "the coefficient of infection") that updates according to revenue. Moreover, this model assumes that players obtain information from others through relationship networks. Because if all the decisions are disclosed, the players will quickly follow a certain player, which will increase price fluctuations.

Interaction: Agents interact with neighbors to know their decision. This local information interaction will form the herding behavior and spread to the entire relationship network eventually.

Stochasticity: Due to the volatility of RE production, the supply of TGC is random.

Observation: The market efficiency is evaluated from two dimensions: the extent of price deviation from value $(D V)$ and price volatility $(V P)$. This model describes herding behavior from the market microstructure perspective. Therefore, the time series of infection coefficient $\left(C I_{i}\right)$ in agent decision-making is referred to as the herding level and the evolution of the herding behavior.

\subsection{Initialization}

This section simulates the operation of the TGC market for 120 trading periods in 10 years. There are $100 \mathrm{RE}$ producers and 100 Discoses in total.

\subsection{Input}

In information asymmetry scenarios, the overall market prediction of value is high, moderate, and low. In combined strategy preference scenarios, the proportional distributions of the three types of strategy preferences are 1: $1: 1,2: 1: 1,1: 2: 1$, and 1: $1: 2$ respectively.

\subsection{Submodels}

\subsubsection{Decision-making}

The final decision of agents includes two parts, the selfdecision based on strategy preference and private information, and the imitation of neighbor decision.

In terms of strategy preference, the survey studies of market participants by Lui and Mole [52] and Menkhoff and Taylor [53] show that most respondents use fundamental and technical analyses in their forecasting of asset price. To distinguish impacts on the herding behavior, three types of behavioral agents are set in the present paper: fundamentalists and technical analysts which contain momentum traders and contrarians.

Fundamentalists and technical analysts represent two kinds of price estimation. Fundamentalists hold that price will approach the fundamental value, but they also have different opinions on the value due to information asymmetry. This model classifies the value information into several grades based on the heterogeneous information trader model in the option market proposed by Schredelseker [54]. The classification of the information based on the precision of the real TGC value means asymmetric information and different access of agents to information. Agents with a higher information grade will make a more accurate prediction on TGC value. In this model, the value of TGC decreases with the progress of technology, as expressed in Eq. (1). For the purpose of completing quota, this model sets the average trading volume of quota requirement in each trading period as the benchmark transaction volume $\left(\overline{B_{t}^{i}}\right)$, which is expressed in Eq. (1). Their transaction volume is determined by the degree of price deviation from the value. If the price is higher than the estimated value, their purchasing volume will be lower than the benchmark amount, as expressed in Eq. (3).

Momentum traders forecast that the price trend is consistent with that in the observation period, while contrarians hold opposite views. For example, if the asset price rises during the observation period, momentum traders will buy more TGCs than the benchmark volume, but contrarians will buy fewer. Their decision functions are expressed in Eqs. (4)-(6).

In terms of herding behavior evolution, each agent has a certain probability $C I$ that updates according to revenue. If the average revenue of neighbors during the memory period $(m p)$ is less than that of agent $i$, then $C I_{i}=$ $C I_{i} \times(1+\mu)\left(0 \leqslant C I_{i} \leqslant 1\right)$, otherwise $C I_{i}=C I_{i} \times(1-\mu)$. Equation (7) indicates the neighbor information of agent $i$ at period $t,\left\langle i, j_{m}\right\rangle$ implies $i, j_{m}$ are neighbors, and $m$ is the number of neighbors. $a_{i, j_{m}}$ is the contribution rate of the neighbor decision of the agent. As expressed in Eq. (8), $N$ is the final decision of neighbors and $a_{i, j_{m}} \geqslant 0 . B_{j_{m}, t-1}$ is the last transaction decision of the neighbor when agent $i$ communicates with neighbor $j_{m}$, and $B_{\mathrm{F}, t}^{i}$ is the final transaction decision of agent $i$. The costs of agents are shown in Eqs. (9) and (10). The costs of the agents who complete the quota are the purchase cost of TGCs, but the agents who do not complete the quota must pay the extra penalty for the uncompleted part. $H_{t}^{i}$ is the amount of TGCs held by the agent after submitting the TGCs.

To specifically study the influence of related factors on herding behavior, this model only describes the herding behavior of Discos. The decision function of the RE producer is expressed in Eq. (11). Assuming that the grid company implements guaranteed full purchase of RE, the average volume of TGC sold in each transaction is set as $\overline{S^{j}}$ based on the estimated annual power generation.

$$
\begin{gathered}
V_{t}=V_{0}-0.0024 t, \\
\overline{B_{t}^{i}}=\frac{Q_{b}^{i}-H_{t}^{i}}{T-t} .
\end{gathered}
$$




$$
\begin{aligned}
B_{\mathrm{F}, t}^{i}= & \left(1-C I_{i}\right) \cdot\left(\overline{B_{t}^{i}}+H_{t}^{i}-\text { Bor }_{i, t}\right) \\
& \cdot\left[\left(\hat{V}_{t}-P_{t-1}\right) \alpha+1\right]+C I_{i} \cdot N_{t-1}^{i},
\end{aligned}
$$

$$
B_{\mathrm{M}, t}^{i}=\left(1-C I_{i}\right) \cdot\left(\overline{B_{t}^{i}}+H_{t}^{i}-\text { Bor }_{i, t}\right) \cdot \operatorname{Trend}^{\beta}+C I_{i} \cdot N_{t-1}^{i},
$$

$$
B_{\mathrm{C}, t}^{i}=\left(1-C I_{i}\right) \cdot\left(\overline{B_{t}^{i}}+H_{t}^{i}-\text { Bor }_{i, t}\right) \cdot \text { Trend }^{-\beta}+C I_{i} \cdot N_{t-1}^{i},
$$

$$
\begin{gathered}
\text { Trend }=\left(P_{t-1-L} / P_{t-1}\right)^{1 / L}, \\
N_{t}^{i}=\sum_{<i, j_{m}>} B_{j_{m}, t-1} \cdot a_{i, j_{m}}, \\
a_{i, j_{m}}=\left(1-C^{j_{m}} / \sum_{i=1}^{m} C^{i}\right) /(m-1), \\
C_{t}^{i}= \begin{cases}P \cdot B_{t}^{i} & \text { if } B_{t}^{i} \geqslant \overline{B_{t}^{i}}, \\
P \cdot B_{t}^{i}+f \cdot\left(\overline{B^{i}}-H_{t}^{i}\right) & \text { if } B_{t}^{i}<\overline{B_{t}^{i}}, \\
H_{t}^{i}=H_{t-1}^{i}+B_{t}^{i}-\operatorname{turn} \text { in }_{t}^{i}, \\
S_{t}^{k}=\overline{S^{j}}(1+\delta)(1+\lambda)\left[\left(P_{t-1}-V_{t}\right) \gamma+1\right] .\end{cases}
\end{gathered}
$$

\subsubsection{Relationship network}

According to the definition of social network [55], behavioral diffusion in social network includes existing social connections or social structures, the behavioral strategies of individual agents, the state of group behaviors caused by interaction among individuals, and the evolution of social network structure due to individual strategy adjustment.

Consequently, this paper uses dynamic scale-free network to describe the network structure among agents, as depicted in Fig. 2. In this network, each node is corresponding to an agent, and the connection among nodes represents the communication between neighbors in the TGC market. The scale-free network is generated as follows.

Step 1: Generate $M$ nodes.

Step 2: Select three nodes randomly and build links among the nodes as the initial network.

Step 3: Randomly select one node from the remaining nodes each time to connect to the existing network according to connection rules.

Step 4: Repeat Step 3 till all the nodes are connected.

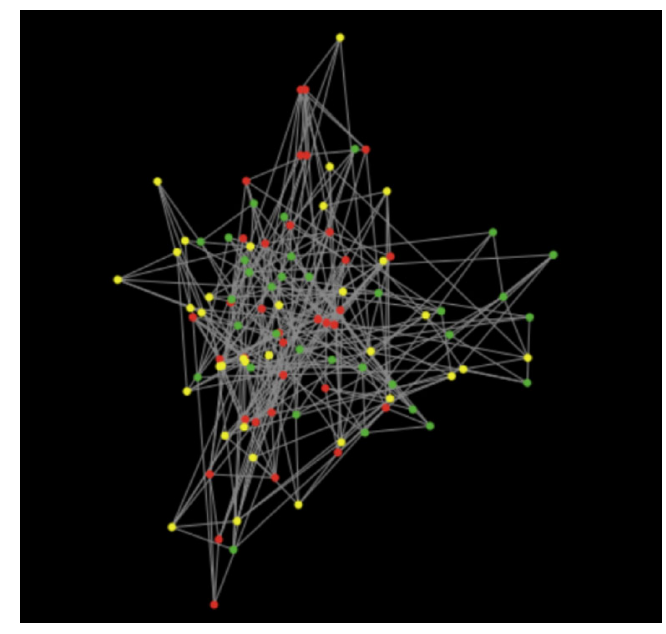

Fig. 2 Scale-free network in ASM-TGC model.

The basic connection rules are as follows.

(1) The connection built is based on the probability of the node being connected in the current network, and the probability is the degree of the node divided by the total degree of the network.

(2) Each node cannot be self-connected, and any two nodes in the network cannot be reconnected.

To characterize the dynamic scale-free network, this model sets that the agents with the lowest return in the network replace current neighbors after each transaction. The specific settings are as follows.

Step 1: The agents with the lowest return break links with current neighbors and select 3 nodes to build links according to basic connection rules.

Step 2: Each of the original neighbors choose one new neighbor according to basic connection rules.

\subsubsection{Market clearing}

This model sets TGC price as the unified clearing price, which is determined by excess demand as expressed in Eq. (12). Equation (13) and (14) are the total supply and demand of TGC [31].

$$
\begin{gathered}
P_{t}=P_{t-1} \cdot \exp \left(\lambda \cdot \frac{D_{t}-S_{t}}{\min \left(S_{t}, D_{t}\right)}\right), \\
S_{t}=\sum_{k} S_{t}^{k}, \\
D_{t}=\sum_{i} B_{t}^{i} .
\end{gathered}
$$

\subsubsection{Market efficiency}

The impacts on market efficiency are evaluated from two 
dimensions: the extent of price deviation from value $(D V)$ and price volatility $(V P)$, which are expressed in Eqs. (15)(17). Because TGC market efficiency is reflected in stimulating RE investment and technological innovation, thus to encourage investment in RE, the TGC price must not only be able to compensate for the cost gap between $\mathrm{RE}$ and conventional energy, but also maintain relatively stable to reduce the risk premium of potential investors as investors estimate future price and expected return based on the price $[57,58]$. But the price of TGC should not be too high, because it is not conducive to forcing RE manufacturers to reduce costs. Therefore, the value of TGC is defined as the long-term marginal cost difference between RE and the conventional energy.

As the TGC price has a downward trend due to the impact of value, the short-term volatility of price is evaluated by measuring the degree of deviation of the price from its moving average $\left(M A_{t}\right)$. The smaller values of $D V$ and $V P$ represent a higher market efficiency.

$$
\begin{gathered}
D V=\sum_{t=1}^{T}\left(V_{t}-P_{t}\right)^{2} / T, \\
V P=\sum_{t=1}^{T}\left(M A_{t}-P_{t}\right)^{2} / T, \\
M A_{t}=\sum_{t-t_{-} m a+1}^{t} P_{t} / t_{-} m a .
\end{gathered}
$$

\section{Simulation and analysis}

\subsection{Data and validation}

This section takes the Chinese TGC market as an example to simulate the evolution of herding behavior. Chinese government has implemented various of remarkable policies to promote the development of the RE industry, of which, the main objective is to expand the financial channels for renewable energy development. The market mechanism in China's RE industry has experienced four periods which are approval tariff, bidding price, FIT (feedin tariff) scheme, and RPS scheme [59]. The Chinese RE electricity trading is experiencing an evolution from the FIT scheme to the RPS scheme, in order to implement the deployment of gradual decline of RE benchmark on-grid price. For photovoltaic (PV) power stations which were put into operation after January 1, 2018, the benchmark prices of classes I, II, and III resource areas are reduced to USD $\$ 85, \$ 100$, and $\$ 115$ per MWh respectively. One of the aims of the TGC scheme is to replace the subsidy in the FIT scheme, thus the value of one TGC is supposed to be the difference between on-grid price of RE and the conventional energy. This paper takes the average benchmark price of PV as the benchmark price of RE which is
$\$ 100$ per MWh. Besides, the benchmark electricity price of desulfurized coal in China is between $\$ 39$ and $\$ 69$ per $\mathrm{MWh}$, the on-grid price of the conventional energy is supposed to be the median of the interval, which is $\$ 54$ per MWh. Based on the above data, the initial value of TGC is $\$ 46$ per MWh [60]. In terms of the penalty, which is to incentive manufacturers to complete quotas, it is supposed to be twice of the TGC price.

It is assumed that the simulation time is 10 years $(120$ months), the start time is January 2019 , and the step size is one month. The key parameters and their initial values are listed in Table 1, most of which are collected from the China Statistical Yearbook and China Energy Outlook 2030. In 2019, the power generation from RE source in China is 2.04 trillion $\mathrm{kWh}$, accounting for $27.9 \%$ and it will reach 2.7625 trillion $\mathrm{kWh}$, accounting for $32.5 \%$ in 2030 . Based on it, the monthly growth rate is $0.25 \%$. As the purpose of the simulation is to study the effect of the herding behavior on the price, it is assumed that the quota is consistent with the expected proportion of RE generation in the total generation.

Based on software Netlogo 6.1.0, this section first studies the impacts of information asymmetry and strategy preference on revenue, then explains evolution characteristics of herding behavior, and finally explores the effects on market efficiency based on evolution path. The agentbased model mainly has three verification methods, the indirect calibration approach, the Werker-Brenner approach, and the history-friendly approach. This paper adopts the Werker-Brenner approach [61]. This simulation is to collect real market data, calibrate relevant parameters, and import them into the model as the initial state of the model. After the model is simulated, the price output by the model is compared with the real market data to verify the effectiveness of the data and the model. The price and value of TGC decrease at the same time, and TGC price drops to 0 at the end of the simulation, which means that with the support of the TGC scheme, the cost of RE decreases and the on-grid parity of RE is realized. The simulation results are consistent with the institutional objectives and verifies the effectiveness of the data and the model [62].

\subsection{Information asymmetry scenarios}

To avoid strategy preference impacts, it is assumed that all the agents adopt the fundamental strategy. TGC market players judge the value of TGC based on fundamental information such as macroeconomics, climate environment, and feed-in tariffs etc. However, due to the incomplete information in the market and the differences in the ability of players to collect, recognize, and analyze information, their judgments of value are biased. To represent their judgement on value, the information is divided into three grades which are presented in Table 2 . 
The prediction of value obeys a uniform distribution centered on the real value. The value estimation in each scenario is tabulated in Table 3. The estimation in Scenarios 2-0 and 2-1 are overall moderate, but comparatively, it is higher and lower in Scenarios 2-2 and 2-3 respectively. To study the role of the herding behavior,

Table 2 Division of information level

\begin{tabular}{lc}
\hline Information level & Value estimation \\
\hline Inf 1 (high grade) & $V$ \\
Inf 2 (medium grade) & $U(V \times 0.5, V \times 1.5)$ \\
Inf 3 (low grade) & $U(V \times 0.1, V \times 1.9)$ \\
\hline
\end{tabular}

Table 3 Value estimation in scenarios

\begin{tabular}{lc}
\hline Scenario & Value estimation \\
\hline $1-0$ & $V, U(V \times 0.1, V), U(V, V \times 1.9)$ \\
$1-1$ & $V, U(V \times 0.1, V), U(V, V \times 1.9)$ \\
$1-2$ & $V, U(V, V \times 1.5), U(V, V \times 1.9)$ \\
$1-3$ & $V, U(V \times 0.5, V), U(V \times 0.1, V)$ \\
\hline
\end{tabular}

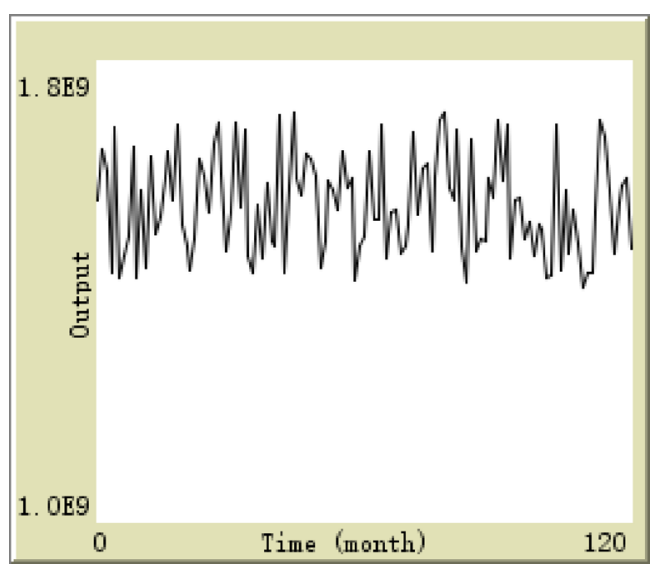

Fig. 3 Output of a renewable energy power plant.

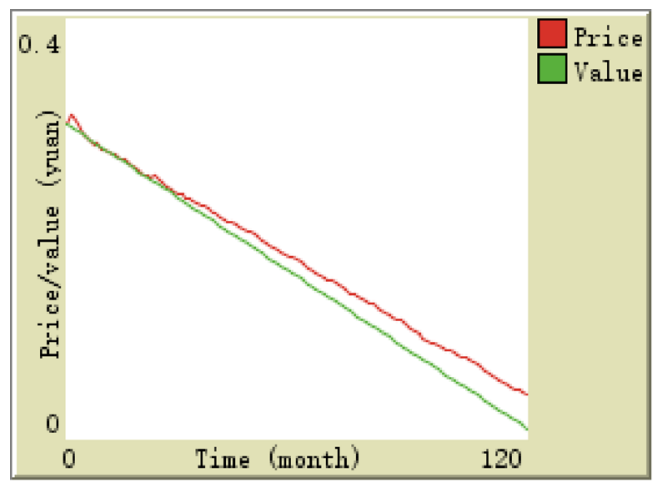

(a) agents do not communicate with neighbors in Scenario 20 . Taking into account the randomness of the RE output, the output of RE producers is displayed in Fig. 3. The TGC price, evolution path of herding, and costs of agents are exhibited in Figs. 4-6, and the market efficiency is given in Table 4.

\subsubsection{Information strategy}

In the TGC market, the interaction between TGC price and herding behavior evolution is shown in Fig. 7. The TGC price fluctuates due to the comprehensive influence of multiple strategies, and the changes of price will, in turn, affect the revenue of agents. The revenue gap among agents leads to herding behavior which means adjustment of strategies.

In terms of information strategy, the closer predicted value to the actual price improves the return of agents. Therefore, the revenue of agents with a higher information grade is higher than that of others. Specifically, in Scenario $1-2$, the cost of Inf 3 agents is higher, because their purchasing amount is higher. Similarly, in scenario 1-3, the cost of Inf 3 agents is also higher than that of others due to the penalty (twice the price) for uncompleted quota.

The cost difference among agents will urge high-cost agents to learn the strategies of low-cost agents, which leads to herding behavior. If the cost of an agent is higher than that of its neighbors in the observation period, its selfconfidence will decrease and the infection coefficient $\left(C I_{i}\right)$ will increase, which implies evolution of herding behavior.

The information strategy of each agent causes the price to converge toward the value it estimates. For example, if the value information held by an agent is $1.5 \mathrm{~V}$ and the price is lower than it, then the agent will purchase more TGC than the benchmark, resulting in an increase in price. Besides, the range of value information represents uncertainty in the demand side. Therefore, it affects price fluctuations. It can be seen that the price is affected by information strategies with different precision, thus its

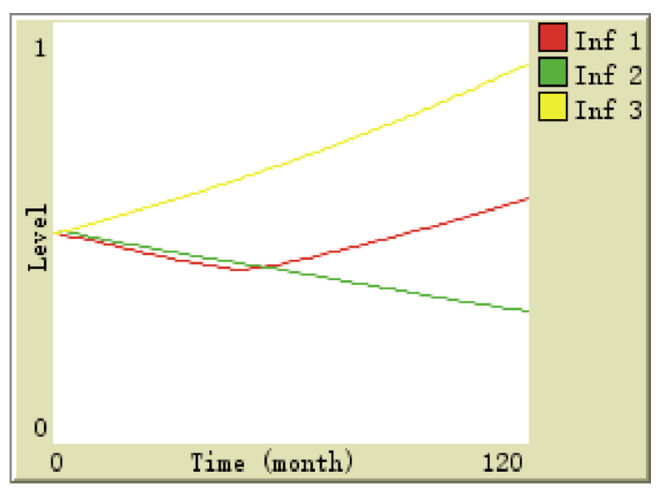

(b)

Fig. 4 Simulation results in Scenario 1-1. (a) Price and value; (b) herding level. 


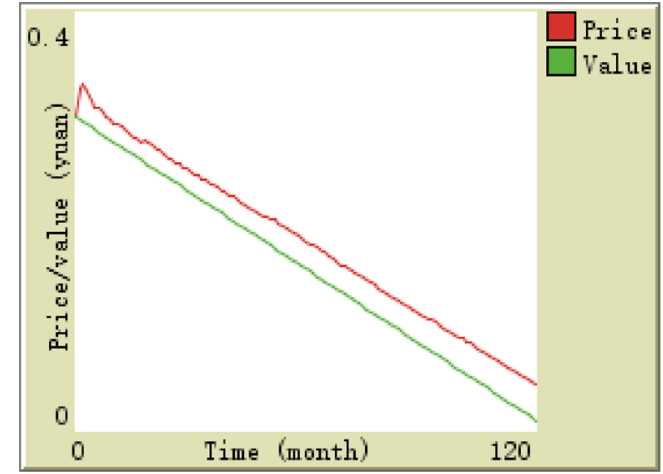

(a)

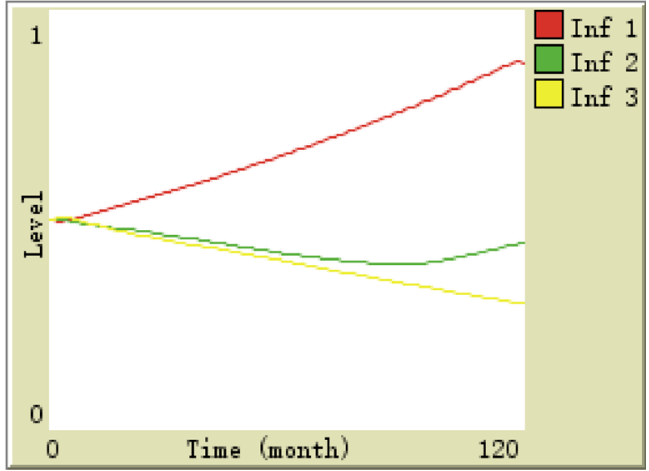

(b)

Fig. 5 Simulation results in Scenario 1-2.

(a) Price and value; (b) herding level.

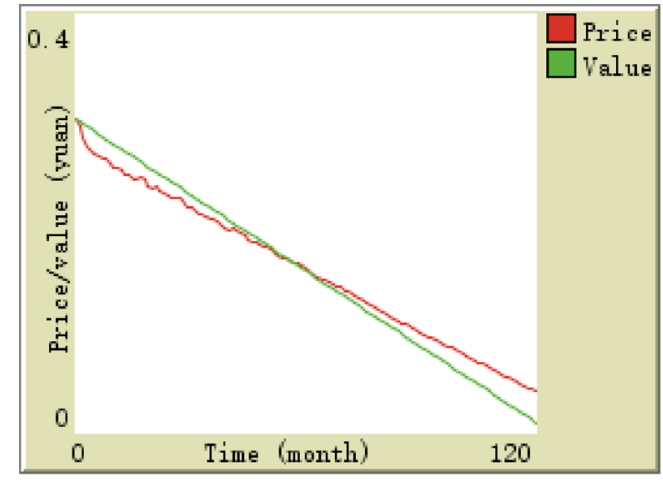

(a)

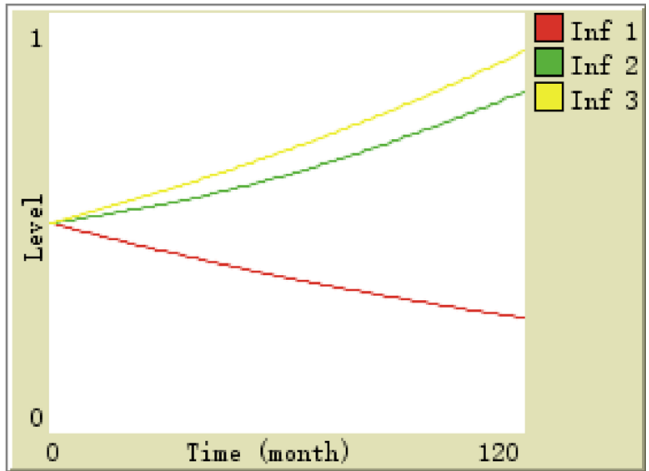

(b)

Fig. 6 Simulation results in Scenario 1-3.

(a) Price and value; (b) herding level.

Table 4 Market efficiency in information asymmetry scenarios

\begin{tabular}{lllll}
\hline Market efficiency & Scenario 1-0 & Scenario 1-1 & Scenario 1-2 & Scenario 1-3 \\
\hline$D V$ & $2.41 \times 10^{-3}$ & $1.15 \times 10^{-4}$ & $5.77 \times 10^{-4}$ & $3.22 \times 10^{-4}$ \\
$V P$ & $3.28 \times 10^{-4}$ & $1.96 \times 10^{-6}$ & $9.80 \times 10^{-6}$ & $1.25 \times 10^{-5}$ \\
\hline
\end{tabular}

Note: Due to random factors such as network node distribution, the values in this table are the average of multiple simulations.

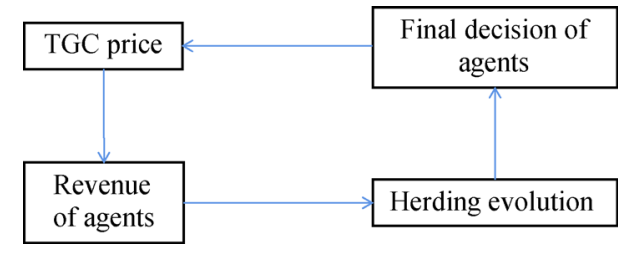

Fig. 7 Interaction between TGC price and herding evolution.

effects on market efficiency depends on the specific scenario of information asymmetry.

\subsubsection{Herding effects on market efficiency}

In Scenario 1-1, although the impact of $\operatorname{Inf} 2-1$ and $\operatorname{Inf} 2-2$ on price basically counteracts each other, the price gradually deviates from value. The reason for this is that the herding level of Inf 2-2 agents is relatively high due to the penalty. Under such circumstances, agents with Inf 1 level lose the cost advantage before, while the herding level of Inf 2-1 agents drops, thus the information which is higher than the true value spreads in the market and increases DV. In Scenario 1-2, the overall value estimation is high. Therefore, the TGC price is also higher than the actual value, resulting in high cost of agents with highprecision information ( $\operatorname{Inf} 1$ ) due to incomplete quota. Comparatively, the estimation of agents with the grade of Inf 2 is closer to the actual price. Thus, their information has advantages. With the decrease of the herding level of agents with Inf 2, their information spreads in the market. As shown in Fig. 4(b), at the beginning, the herding level 
of $\operatorname{Inf} 1$ and $\operatorname{Inf} 2$ decline together, hence, both $\operatorname{Inf} 1$ and $\operatorname{Inf}$ 2 are dominant strategies. However, Inf 1 agents gradually lose the dominant position because price is higher than their expectation. As Inf 2 agents predict price more accurately, their herding level continues to decline. In Scenario 1-3, the overall value estimation is relatively low. Both the Inf 2 and Inf 3 agents will pay penalties due to incomplete quota, hence, their cost is significantly higher. In this scenario, Inf 1 information strategy is always in an advantageous position, whose evolution promotes the spread of high-precision information and brings price to real value.

The value of $D V$ and $V P$ is mainly related to the initial information asymmetry environment, and is lower in scenarios where the overall estimation on value is higher or lower. However, it can be improved by herding evolution. A comparison of Scenarios 1-0 and 1-1 suggests that the evolution of herding behavior triggered by information asymmetry improves market efficiency. The reason for this is that the revenue of "Inf 1 " agents is higher than that of others, thus, the evolution facilitates the spread of their high precision information and reduces the fluctuation range of value information. This indicates that although
$D V$ and $V P$ are affected by initial information grade, herding evolution can be interfered to improve market efficiency. A comparison of Scenarios 1-2 and 1-3 demonstrates that the spread of high-quality information improves market efficiency. The reason for the fact that the DV in Scenario 1-2 higher than that in Scenario 1-3 although their information grade is similar is that Inf 1 strategy sustains the dominant position in Scenario 1-3, as shown in Fig. 5(b) and Fig. 6(b), but Inf 1 strategy in Scenario 1-2 losses its dominant position in the later stage and Inf 2 strategy dominates in the whole process.

\subsection{Strategy preference scenarios}

Three types of strategy preferences are set, including fundamental, momentum and contrarian strategy. Four scenarios are established, in which the TGC transaction is simulated with and without herding respectively, and their ratios of number are $1: 1: 1,2: 1: 1,1: 2: 1$, and $1: 1: 2$ in Scenarios from 2 to 1 to $2-4$. The market efficiency in each scenario is presented in Table 5, and the price trends and evolution paths of herding behavior are displayed in Figs. 8-11.

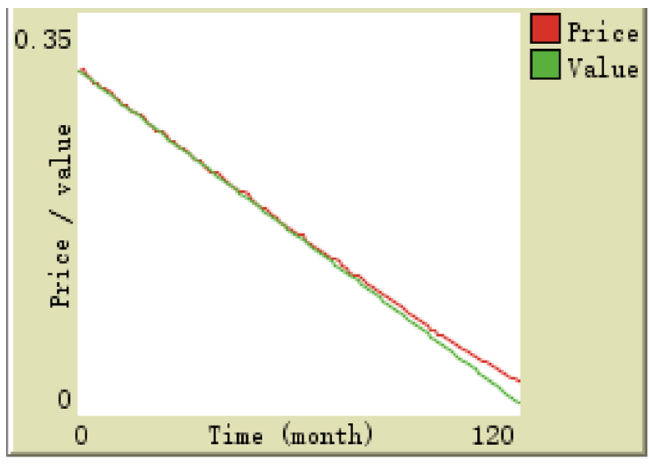

(a)

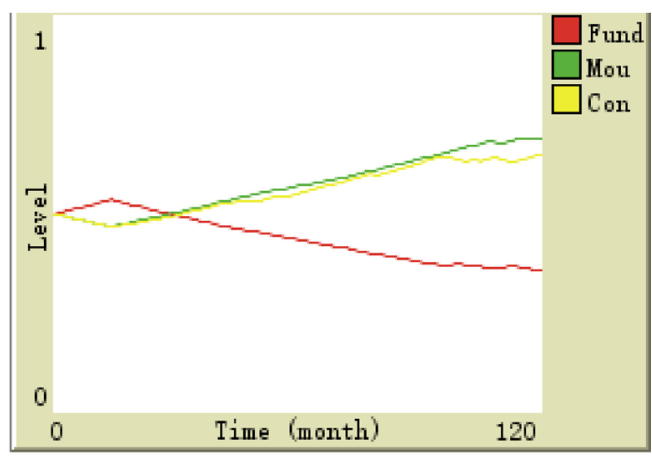

(b)

Fig. 8 Simulation results in Scenario 2-1 (1:1:1).

(a) Price and value; (b) herding level.

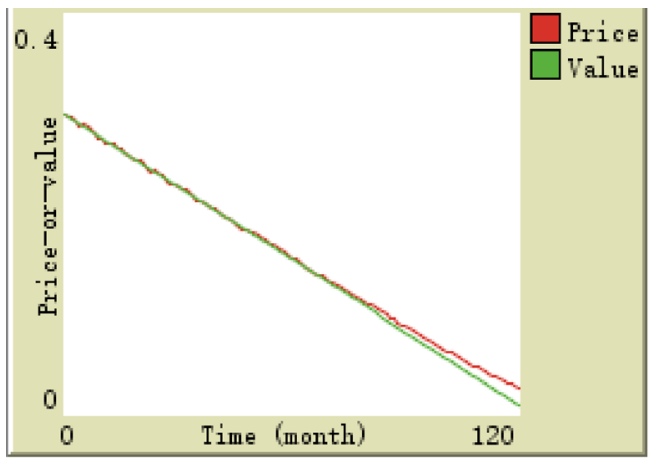

(a)

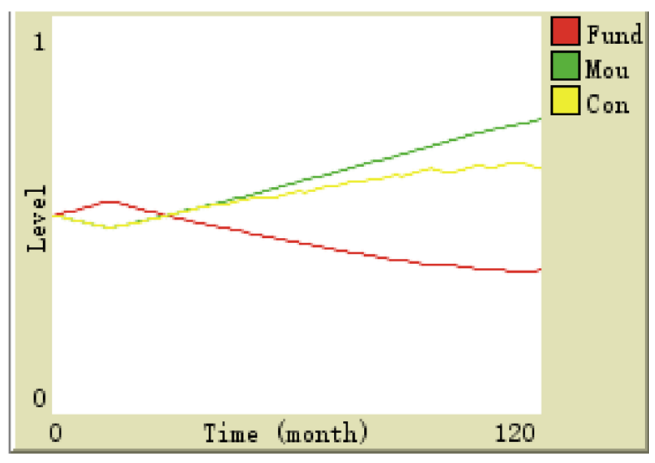

(b)

Fig. 9 Simulation results in Scenario 2-2 (2:1:1).

(a) Price and value; (b) herding level. 


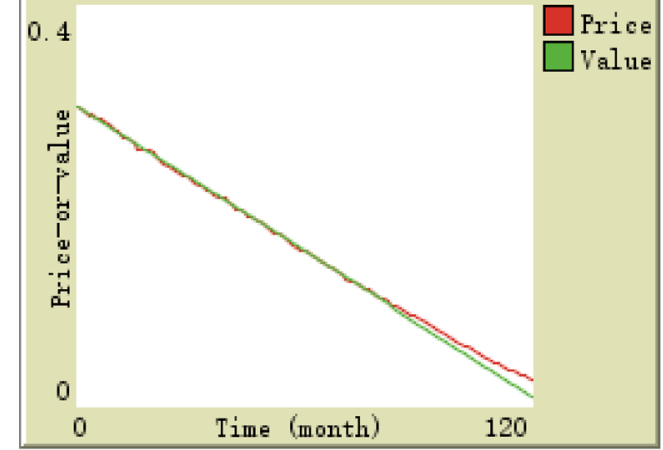

(a)

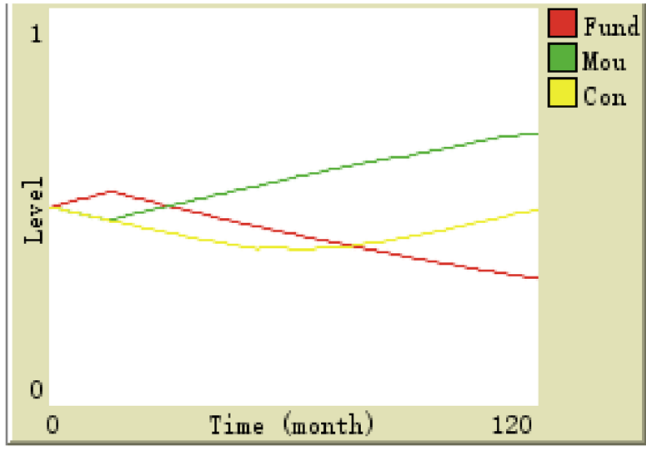

(b)

Fig. 10 Simulation results in Scenario 2-3 (1:2:1).

(a) Price and value; (b) herding level.

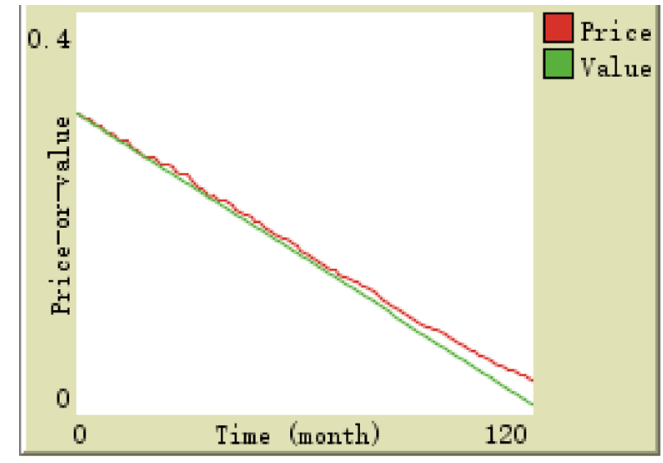

(a)

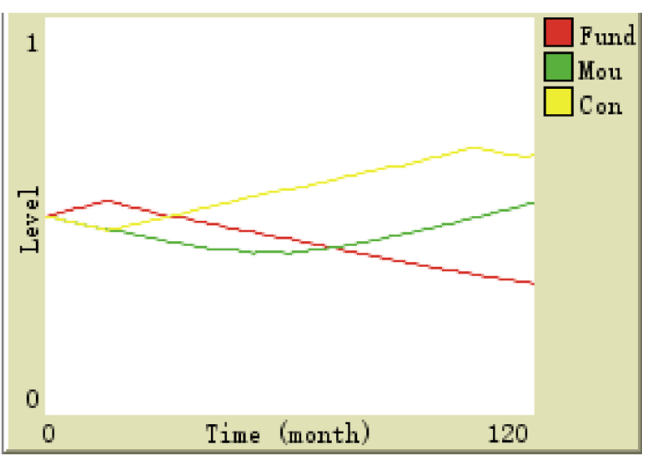

(b)

Fig. 11 Simulation results in Scenario 2-4 (1:1:2).

(a) Price and value; (b) herding level.

\subsubsection{Strategy preference}

Herding behavior is caused by income difference due to strategy preference. The three strategies are based on price expectation; thus, costs will be relatively low only when future price is consistent with their expectations. If the cost of an agent is higher than that of neighbors, its strategy is disadvantaged and its herding level will increase. Owing to different judgments on future price, their impacts on price also differ. Regardless of the price trend, the decision of fundamentalists leads the price to converge to its estimated value. If price is on the rise, momentum traders will buy more certificates while contrarians purchase fewer. Thus, their impacts on price are opposite, the former will exacerbate past price trend while the latter will reverse it.

\subsubsection{Herding effects on market efficiency}

In various of scenarios, the evolution path of each strategy differs. In Scenarios 2-1 and 2-2, as shown in Figs. 8(b) and 9(b), two trend strategies are dominant in the early period, but with the dissemination of them, their costs begin to increase due to the penalty or a too large purchase volume. Comparatively, the herding level of fundamentalists begin to decline as their trading volume is appropriate. In Scenario 2-3, as shown in Fig. 10(b), the evolution path is similar to that of Scenario 2-1 (2-2) on the whole, only the herding level of contrarians is lower. The reason for this is that minor contrarians have more opportunities to contact with neighbors. Therefore, their costs are significantly lower than those of momentum traders. For the same reason, the herding level of momentum traders is lower than that of contrarians in Scenario 2-4, as shown in Fig. 11(b). The results indicate that a higher proportion of the trend strategy leads to its higher herding level. Additionally, in the later stage of evolution, the herding level of some agents no longer continues to rise or fall, but fluctuates at a certain level, which indicates that their strategy combination does not have a comparative advantage or disadvantage. Typically, in Fig. 8(b), the herding levels of three types of agents remain at a certain level. This result illustrates herding evolution updates the strategies of agents, reduces the cost gap among them, and makes the cost allocation fairer. It also proves that the evolution of herding behavior will eventually reach an equilibrium so that the benefits of agents are comparable. 
Table 5 Market efficiency in combined strategy preference scenarios

\begin{tabular}{|c|c|c|c|c|}
\hline \multirow{2}{*}{ Market efficiency } & \multicolumn{2}{|c|}{$2-1(1: 1: 1)$} & \multicolumn{2}{|c|}{$2-2(2: 1: 1)$} \\
\hline & No herding & Herding & No herding & Herding \\
\hline$\overline{D V}$ & $5.06 \times 10^{-5}$ & $5.21 \times 10^{-5}$ & $3.96 \times 10^{-5}$ & $4.36 \times 10^{-5}$ \\
\hline$V P$ & $1.43 \times 10^{-6}$ & $1.54 \times 10^{-6}$ & $1.66 \times 10^{-6}$ & $1.77 \times 10^{-6}$ \\
\hline \multirow{2}{*}{ Market efficiency } & \multicolumn{2}{|c|}{$2-3(1: 2: 1)$} & \multicolumn{2}{|c|}{$2-4(1: 1: 2)$} \\
\hline & No herding & Herding & No herding & Herding \\
\hline$\overline{D V}$ & $1.72 \times 10^{-5}$ & $3.75 \times 10^{-5}$ & $1.28 \times 10^{-4}$ & $9.55 \times 10^{-5}$ \\
\hline$V P$ & $1.94 \times 10^{-6}$ & $2.71 \times 10^{-6}$ & $2.24 \times 10^{-6}$ & $1.63 \times 10^{-6}$ \\
\hline
\end{tabular}

The difference of $D V$ and $V P$ among scenarios is mainly caused by the diverse initial proportion of strategy preferences. This shows that the market efficiency in Scenario 2-1 is the highest for the majority of fundamentalists. Compared with Scenario 2-1, the DV in Scenario 22 is higher because the dominance of the fundamentalists makes the price closer to the value. This demonstrates that the increase of fundamentalists will improve market efficiency and their revenue is higher than that of others, hence agents should be encouraged to adopt the fundamental strategy. The $D V$ in Scenario 2-3 is the lowest in several scenarios but the $V P$ is relatively higher, because the momentum strategy accelerates the decline of price reducing the $D V$, but fundamental and contrarian strategies increase volatility when the price is lower than value. In Scenario 2-4 where contrarians are the majority, both the $D V$ and $V P$ are the highest among scenarios. The reason for this is that the contrarian strategy suppresses the decline of price and intensifies fluctuations. The comparison shows that the evolution of herding behavior in both Scenarios 21 and 2-2 depresses market efficiency, because the impacts of momentum and contrarian strategies are canceled out if there is no herding behavior, but the effect of the contrarian strategy on enhancing volatility becomes relative greater and the effect of the momentum strategy on depressing price becomes weaker with herding evolution. In Scenario 2-3, evolution reduces market efficiency. With the increasing herding level of the momentum strategy, its effect on lowering price is weakened. Besides, the decreased herding level of the contrarian strategy intensifies its influence on enhancing volatility. Similarly, in Scenario 2-4, the herding evolution promotes market efficiency, because of increased herding level of the contrarian strategy and decreased herding level of the momentum strategy.

\section{Discussion}

\subsection{Regulatory rules in TGC market}

To ensure the effective operation of the TGC market, policy makers should formulate some regulatory rules, such as penalty, banking and borrowing mechanisms. These regulatory rules can guide the market participants to make reasonable decisions and encourage them to imitate strategies that are conducive to increase market efficiency [62]. In this section, the banking and borrowing mechanism in above scenarios is introduced considering penalty, to compare the effects of unlimited and limited valid lifetime of TGC, borrowing with interests and penalty on herding evolution and market efficiency.

\subsubsection{Penalty}

In a TGC system in which demand is driven by an obligation, penalties are key elements. In the TGC market, price caps and price floors are set to secure the consumer/ producers against high/low prices, and the penalty is generally equal to price cap to incentive manufacturers to complete obligations. In this paper, to study the effect of herding behavior on TGC price, price caps and price floors are not introduced, but the penalty is set to be twice the price of TGC.

\subsubsection{Banking}

Banking is assumed to have a price smoothing effect, and certificates have a valid lifetime longer than the yearly compliance period of consumers. This mechanism is referred to as banking, where producers and consumers can choose in periods of low prices (i.e., windy years) to store certificates for later years. A longer valid time indicates market players possibly purchase more certificates, which raises the price.

\subsubsection{Borrowing}

If the number of the certificates handed over is less than the number of the certificates required, the borrowing mechanism allows participants to fulfil their obligations in the future and would also increase the certificate demand. The interest rate is generally considered to incentive RE production and should be higher than the average interest rate for RE investment loans. 


\subsection{Impact of regulatory rules}

\subsubsection{Impact of regulatory rules in information asymmetry} scenarios

From the analysis in Section 5, it can be seen that the evolution of herding has reduced the degree of information asymmetry and decreased the $D V$ and $V P$, which shows that even if the regulatory rules are not adjusted, the evolution of the herding behavior can also increase expectations of potential investors. Nevertheless, the evolution path shows that only the continued decline in the level of the herding of players with high-precision information can show that high-precision information has spread to the entire market to the greatest extent. When the market value expectation is moderate or higher, the expectation of high-quality information players is lower than the market price, and the penalty will be paid due to insufficient purchase quantity. To promote the diffusion of their strategies, their costs can be appropriately reduced by borrowing with interests. The TGC price and herding evolution path in scenarios where the limited valid lifetime of the TGC and borrowing mechanism are introduced are shown in Figs. 12-14 and the market efficiency is shown in Table 6.

In the scenarios where the value expectation is moderate or higher, the introduction of borrowing significantly improves the market efficiency and changes the evolution path of herding behavior. The level of herding behavior of high-quality information strategy always declines; thus the herding evolution promotes the diffusion of high-precision information. The reason for this is that the subjects with a lower price expectation complete the quota by borrowing and it is not necessary to optimize the strategy by imitating the subject with a higher expectation. Therefore, the diffusion of the lowquality strategy is restrained, and only high-precision information can be diffused. In the situation of a lower value expectation, due to the fact that the diffusion of high-precision information is diffused by herding evolution, the valid lifetime and borrowing mechanism do not play a significant role.

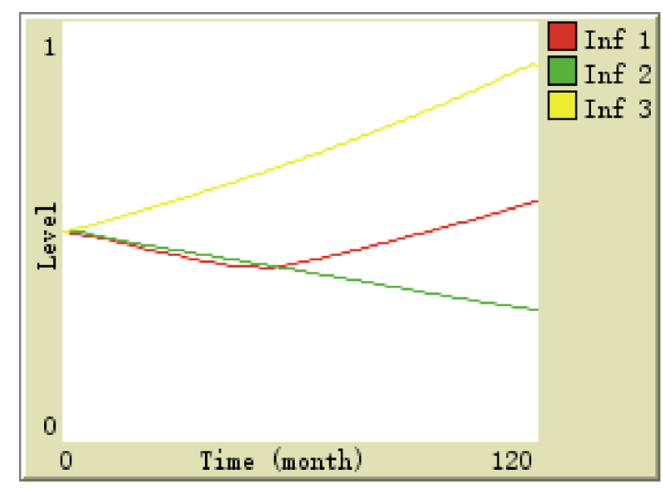

(a)

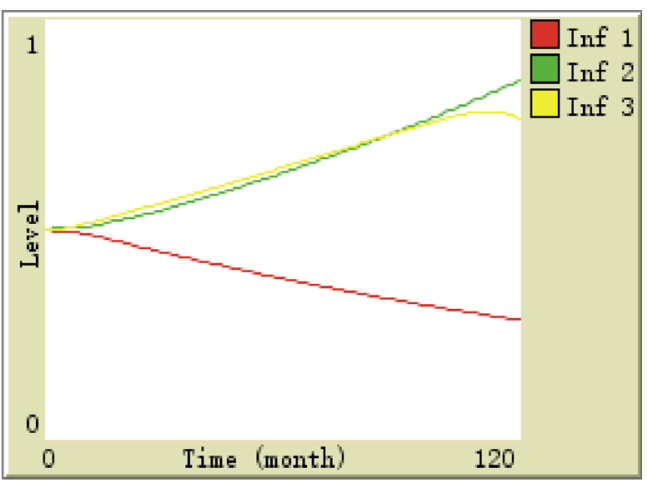

(b)

Fig. 12 Impacts of regulatory rules in Scenario 1-1.

(a) Limited valid lifetime; (b) borrowing.

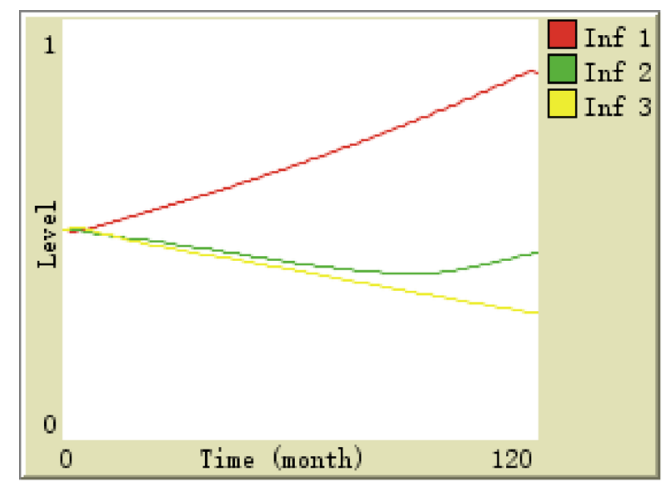

(a)

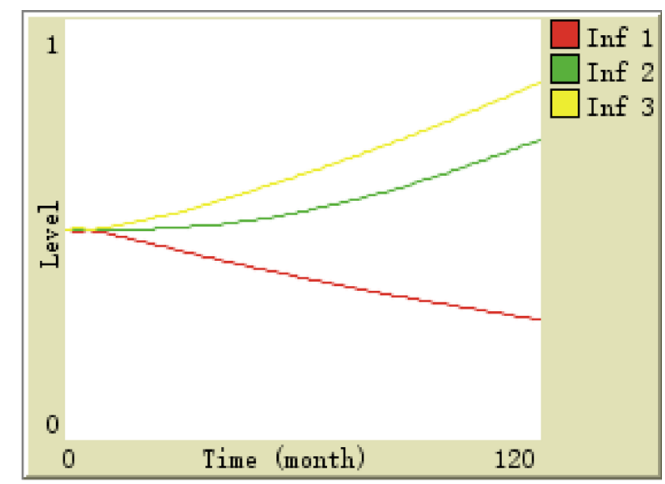

(b)

Fig. 13 Impacts of regulatory rules in Scenario 1-2. (a) Limited valid lifetime; (b) borrowing. 
6.2.2 Impact of regulatory rules in strategy preference scenarios

For the evolution of the herding caused by strategy preference, DV and VP can be reduced only when the contrarian strategy is dominant. According to the analysis in Section 5, the diffusion of fundamental strategies helps to make the price tend to be value, but the two trend strategies increase the price volatility. In the four scenarios,

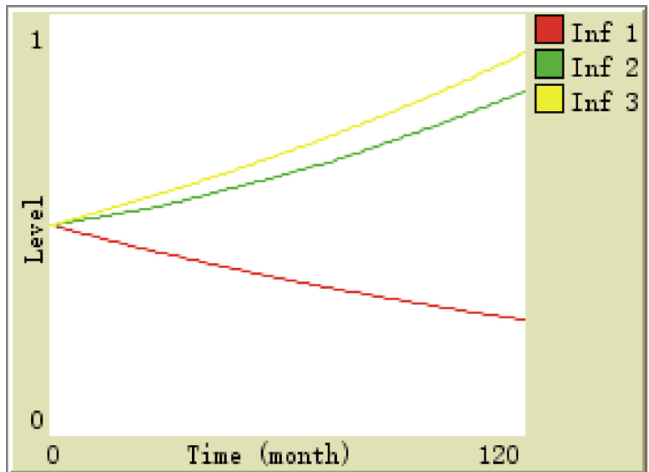

(a) herding evolution promotes the diffusion of fundamental strategies in the long run, but also the diffusion of trend strategies in the short-term. Therefore, in order to further enhance the diffusion effect of herd evolution on the fundamental strategy and restrain the diffusion of trend strategy, limited valid time and borrowing mechanism can be considered. The TGC price and herding evolution path are shown in Figs. 15-18 while the market efficiency is shown in Table 7.

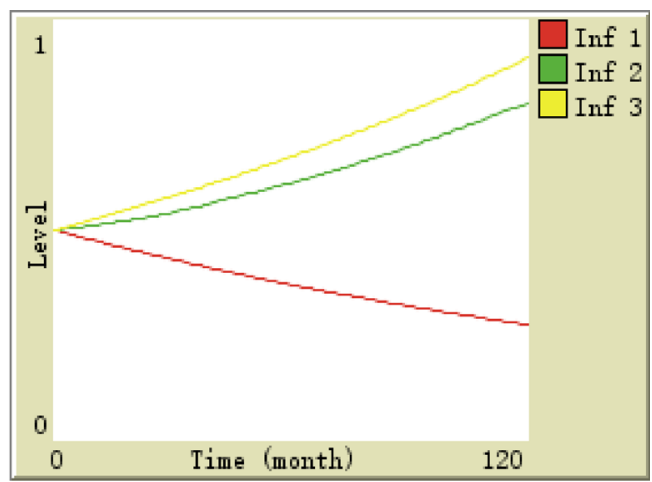

(b)

Fig. 14 Impacts of regulatory rules in Scenario 1-3.

(a) Limited valid lifetime; (b) borrowing.

Table 6 Impacts of regulatory rules on market efficiency in information asymmetry scenarios

\begin{tabular}{lcccc}
\hline & Market efficiency & Scenario 1-1 & Scenario 1-2 & Scenario 1-3 \\
\hline Unlimited valid time and fine & $D V$ & $1.15 \times 10^{-4}$ & $5.77 \times 10^{-4}$ & $3.22 \times 10^{-4}$ \\
Limited valid time and fine & $V P$ & $1.96 \times 10^{-6}$ & $9.80 \times 10^{-6}$ & $1.25 \times 10^{-5}$ \\
& $D V$ & $1.25 \times 10^{-4}$ & $6.07 \times 10^{-4}$ & $3.58 \times 10^{-4}$ \\
Limited valid time, borrowing and fine & $V P$ & $1.87 \times 10^{-6}$ & $9.68 \times 10^{-6}$ & $1.98 \times 10^{-5}$ \\
& $D V$ & $9.96 \times 10^{-5}$ & $8.51 \times 10^{-5}$ & $2.86 \times 10^{-4}$ \\
& $V P$ & $7.80 \times 10^{-7}$ & $6.22 \times 10^{-6}$ & $1.55 \times 10^{-5}$ \\
\hline
\end{tabular}

Note: Due to random factors such as network node distribution, the values in Table 6 are the average of multiple simulations.

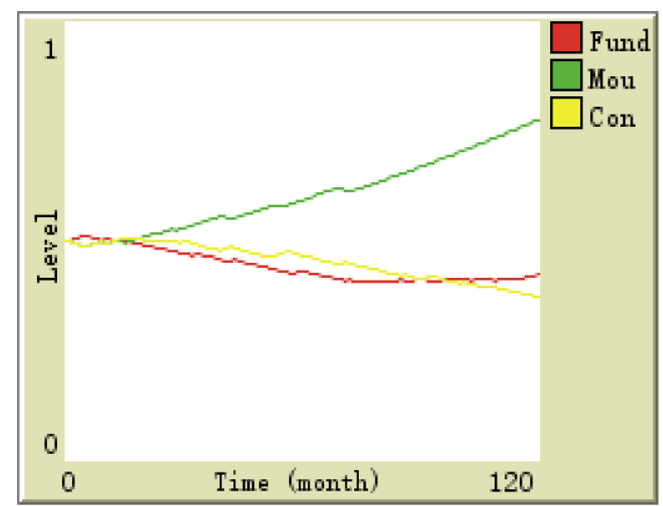

(a)

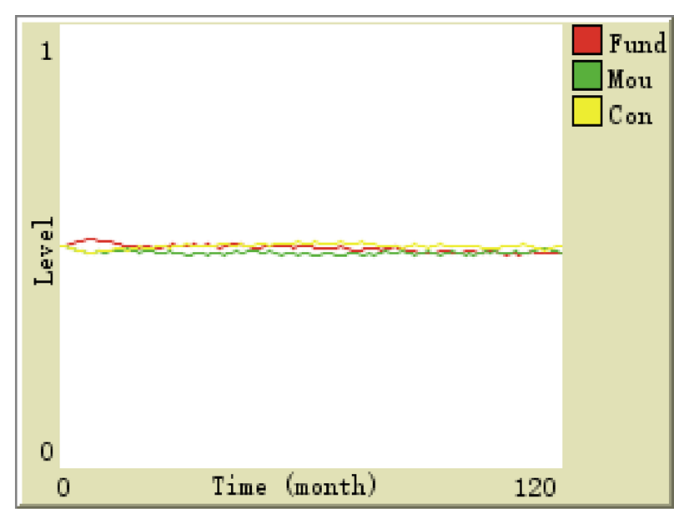

(b)

Fig. 15 Impacts of regulatory rules in Scenario 2-1.

(a) Limited valid lifetime; (b) borrowing. 


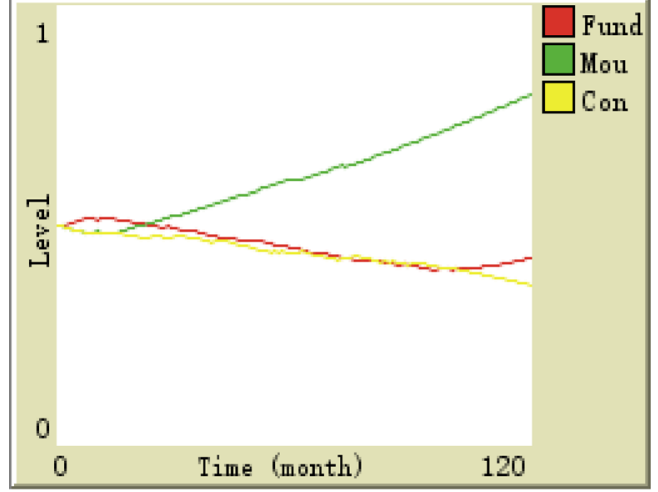

(a)

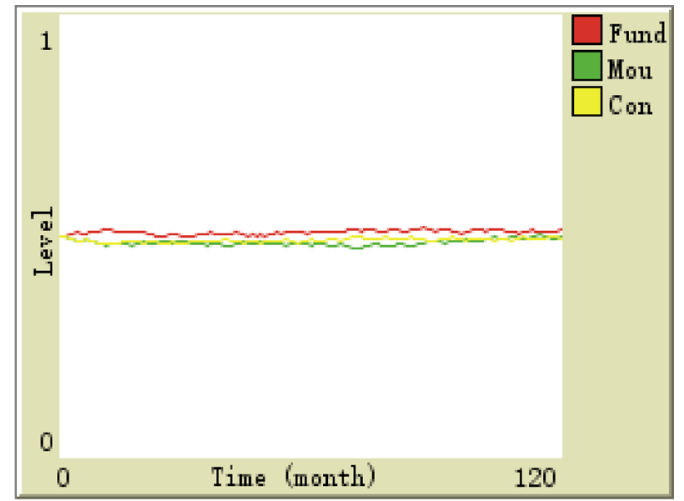

(b)

Fig. 16 Impacts of regulatory rules in Scenario 2-2.

(a) Limited valid lifetime; (b) borrowing.

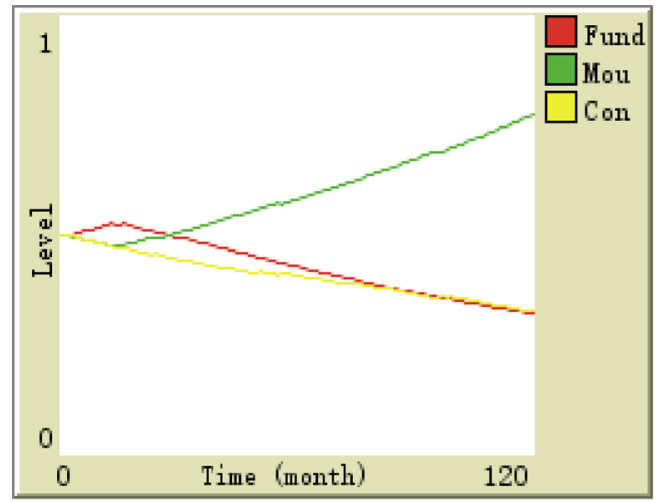

(a)

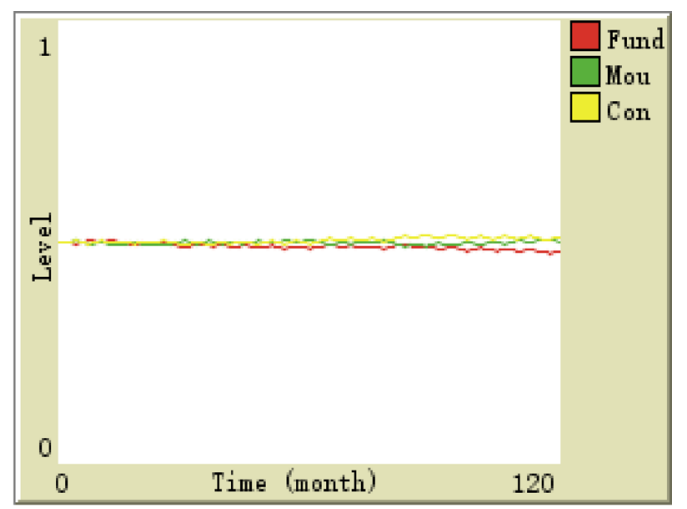

(b)

Fig. 17 Impacts of regulatory rules in Scenario 2-3.

(a) Limited valid lifetime; (b) borrowing.

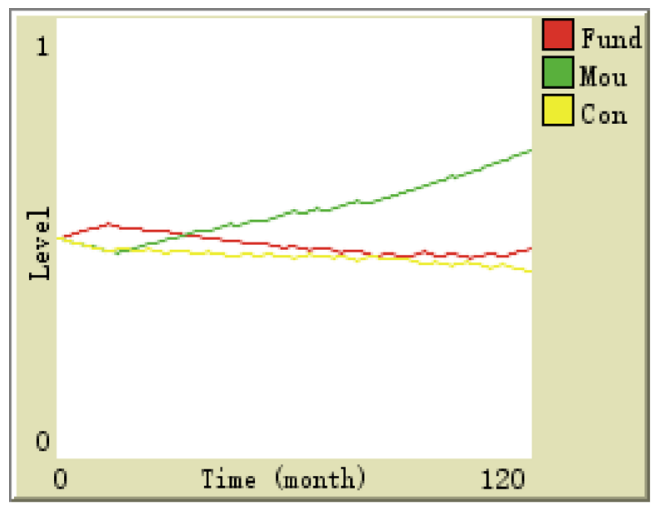

(a)

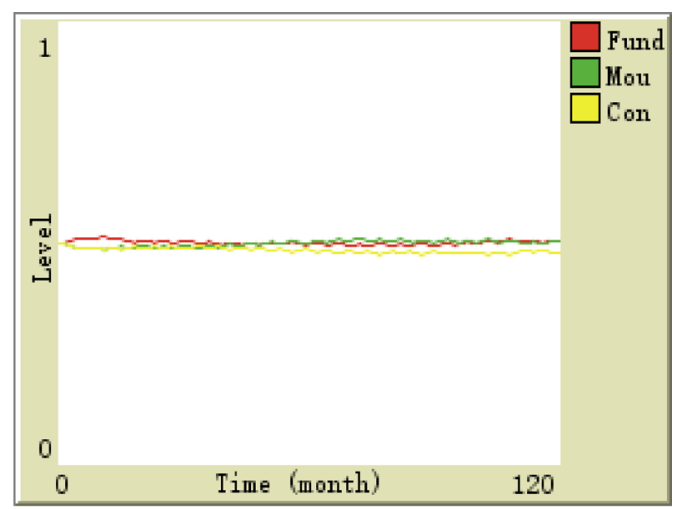

(b)

Fig. 18 Impacts of regulatory rules in Scenario 2-4.

(a) Limited valid lifetime; (b) borrowing.

In these scenarios, market efficiency increases remarkably when the borrowing mechanism is introduced, but the limited valid lifetime has little effect on market efficiency.
The borrowing mechanism updates the strategies of agents, inhibiting the diffusion of the fundamental strategy, thus their herding levels are comparable, and trend strategies 
Table 7 Impacts of regulatory rules on market efficiency in strategy preference scenarios

\begin{tabular}{lccccc}
\hline & Market efficiency & $2-1(1: 1: 1)$ & $2-2(2: 1: 1)$ & $2-3(1: 2: 1)$ & $2-4(1: 1: 2)$ \\
\hline Unlimited valid time and fine & $D V$ & $5.21 \times 10^{-5}$ & $4.36 \times 10^{-5}$ & $3.75 \times 10^{-5}$ & $9.55 \times 10^{-5}$ \\
& $V P$ & $1.54 \times 10^{-6}$ & $1.77 \times 10^{-6}$ & $2.71 \times 10^{-6}$ & $1.63 \times 10^{-6}$ \\
Limited valid time and fine & $D V$ & $4.97 \times 10^{-5}$ & $4.78 \times 10^{-5}$ & $4.18 \times 10^{-5}$ & $9.29 \times 10^{-5}$ \\
& $V P$ & $1.29 \times 10^{-6}$ & $1.93 \times 10^{-6}$ & $2.24 \times 10^{-5}$ & $2.03 \times 10^{-6}$ \\
Limited valid time, borrowing and fine & $D V$ & $4.53 \times 10^{-4}$ & $8.39 \times 10^{-5}$ & $3.09 \times 10^{-4}$ & $6.17 \times 10^{-4}$ \\
& $V P$ & $1.37 \times 10^{-5}$ & $1.58 \times 10^{-5}$ & $4.65 \times 10^{-5}$ & $4.91 \times 10^{-5}$ \\
\hline
\end{tabular}

Note: Due to random factors such as network node distribution, the values in Table 7 are the average of multiple simulations.

cause much more fluctuations on price. However, limited valid lifetime does not change the herding evolution path, thus has little effect.

\section{Conclusions and policy implications}

In this paper, an ASM-TGC model containing multiple heterogeneous, adaptive agents, and TGC market regulatory rules is established to simulate TGC trading in a variety of scenarios in which herding evolution is triggered by information asymmetry and strategy preference. Therefore, using such a simulation instrument can well assist both the regulators, in choosing appropriate policies and market players, in testing the efficiency of trading strategies, either in the operating phase or in the initial design stage of TGC and other energy market. Some exogenous parameters mentioned in the model description are known as the regulatory rules in the TGC market which can be adjusted by the regulatory authority or policy makers for decision making. This paper analyzes the characteristics and principles of the herding behavior market players, especially its effects on TGC market efficiency. Based on the influencing mechanism of herding and the function of regulatory rules, the effects of penalty banking and borrowing mechanism are simulated and compared. The main conclusions are as follows.

The evolution of the herding behavior driven by information asymmetry improves market efficiency, as it promotes the diffusion of more accurate information. If overall estimation on value is moderate, the diffusion of higher medium grade information is promoted; If estimation is higher, medium grade information is diffused; if estimation is lower, high grade information is spread.

The evolution of the herding behavior driven by strategy preference improves market efficiency only when the contrarian strategy is dominant in the initial proportion. Although the herding evolution promotes the spread of the fundamental strategy, the trend strategy is also diffused in the scenarios where its initial proportion is higher.

Herding behavior improves fairness in TGC market and is eventually possible to evolve to an equilibrium state where the benefits of market players are comparable.
The introduction of borrowing mechanism may significantly affect the herding evolution and its function, but limited valid lifetime has little effects. The herding behavior with borrowing promotes the diffusion of highquality information and increases the market efficiency when the value expectation is moderate or higher in information asymmetry but makes market efficiency decreases remarkably in the strategy preference scenarios where the herding level of the three kinds of strategies are comparable.

Although TGC market efficiency is mainly determined by the initial information environment and strategy combination, it can be improved by the evolution of the herding with the guidance of regulatory rules. Based on the mechanism of effects of herding evolution, adjustments of regulatory rules are given as follows.

The market efficiency can be further improved in information asymmetry scenarios. If overall estimation on value is moderate or higher, regulatory authorities should appropriately reduce penalty and the valid time of TGC and increase the proportion of TGC borrowed; if overall estimation is lower, regulatory authorities should appropriately increase the penalty, reduce the proportion of borrowing available, and extend the valid period.

To further enhance the diffusion effect of herding evolution on the fundamental strategy and restrain the diffusion of the trend strategy, regulatory authorities should increase the penalty, reduce the amount of TGCs borrowed, and shorten the valid time.

The government should broaden the communication channels of market players to improve fairness of revenue allocation and encourage players to adopt the fundamental strategy as it is both beneficial to the revenue of individuals and market efficiency.

The borrowing mechanism can be introduced when high quality information or the fundamental strategy cannot spread with herding evolution. The government should improve the information disclosure system and increase the openness of information to ensure that timely, sufficient, and accurate information is provided to the market.

This paper provides a reference for the government to guide the transaction behavior of players to improve 
market efficiency. In the future, further research will be conducted from the following aspects: (1) consider the self-learning mechanism of players for maximizing benefits, and quantitatively study the optimal strategy of players, (2) study the relevant market parameter based on the evolutionary equilibrium strategy in the dynamic network.

Acknowledgements This paper was supported by the Beijing Municipal Social Science Foundation (No. 16JDYJB031) and the Fundamental Research Funds for the Central Universities (No. 2020YJ008).

\section{References}

1. IEA. Global $\mathrm{CO}_{2}$ emissions in 2019. 2020, available at website of IEA

2. United Nations Environment Programme. Emissions Gap Report 2019. 2020

3. Zenghelis D, Agarwala M, Coyle D, et al. Valuing Wealth, Building Prosperity. The Wealth Economy Project on Natural and Social Capital, One Year Report. Bennett Institute for Public Policy, Cambridge, 2020

4. Blyth W, Gross R, Speirs J, et al. Low Carbon Jobs: The Evidence for Net Job Creation from Policy Support for Energy Efficiency and Renewable Energy. London: UK Energy Research Centre, 2014

5. Barbose G. US Renewables Portfolio Standards: 2017 Annual Status Report. Lawrence Berkeley National Lab., Berkeley, CA, USA, 2017

6. Agnolucci P. The effect of financial constraints, technological progress and long-term contracts on tradable green certificates. Energy Policy, 2007, 35(6): 3347-3359

7. Darmani A, Rickne A, Hidalgo A, et al. When outcomes are the reflection of the analysis criteria: a review of the tradable green certificate assessments. Renewable \& Sustainable Energy Reviews, 2016, 62: 372-381

8. BenSaïda A. Herding effect on idiosyncratic volatility in US industries. Finance Research Letters, 2017, 23: 121-132

9. Economou F, Gavriilidis K, Gregoriou G, et al. Handbook of Investors' Behavior During Financial Crises. Pittsburgh: Academic Press, 2017, 151-168

10. Júnior G S R, Palazzi R B, Klotzle M C, et al. Analyzing herding behavior in commodities markets - an empirical approach. Finance Research Letters, 2020, 35: 101285

11. Wang H, Zhao X G, Ren L Z, et al. An agent-based modeling approach for analyzing the influence of market participants' strategic behavior on green certificate trading. Energy, 2021, 218 : 119463

12. Palao F, Pardo A. Do carbon traders behave as a herd? North American Journal of Economics and Finance, 2017, 41: 204-216

13. Brunetti C, Buyuksahin B, Harris J H. Herding and speculation in the crude oil market. Energy Journal, 2013, 34(3): 83-104

14. Hirshleifer D, Hong Teoh S. Herd behaviour and cascading in capital markets: a review and synthesis. European Financial Management, 2003, 9(1): 25-66

15. Chauhan Y, Ahmad N, Aggarwal V, et al. Herd behaviour and asset pricing in the Indian stock market. IIMB Management Review, 2020, 32(2): 143-152

16. Nielsen L, Jeppesen T. Tradable Green Certificates in selected European countries-overview and assessment. Energy Policy, 2003, 31(1): 3-14

17. Ghaffari M, Hafezalkotob A, Makui A. Analysis of implementation of Tradable Green Certificates system in a competitive electricity market: a game theory approach. Journal of Industrial Engineering International, 2016, 12(2): 185-197

18. Hasani-Marzooni M, Hosseini S H. Trading strategies for wind capacity investment in a dynamic model of combined tradable green certificate and electricity markets. IET Generation, Transmission \& Distribution, 2012, 6(4): 320-330

19. Zuo Y, Zhao X G, Zhang Y Z, et al. From feed-in tariff to renewable portfolio standards: an evolutionary game theory perspective. Journal of Cleaner Production, 2019, 213: 1274-1289

20. Vogstad K, Kristensen I S, Wolfgang O. Tradable green certificates: the dynamics of coupled electricity markets. In: Proceedings of System Dynamics Conference, New York, USA, 2003

21. An X, Zhang S, Li X, et al. Two-stage joint equilibrium model of electricity market with tradable green certificates. Transactions of the Institute of Measurement and Control, 2019, 41(6): 1615-1626

22. Maug E, Naik N. Herding and delegated portfolio management: the impact of relative performance evaluation on asset allocation. Quarterly Journal of Finance, 2011, 1(02): 265-292

23. Huang T C, Lin B H, Yang T H. Herd behavior and idiosyncratic volatility. Journal of Business Research, 2015, 68(4): 763-770

24. Yamamoto R. Volatility clustering and herding agents: does it matter what they observe? Journal of Economic Interaction and Coordination, 2011, 6(1): 41-59

25. Lakonishok J, Shleifer A, Vishny R W. The impact of institutional trading on stock prices. Journal of Financial Economics, 1992, 32 (1): $23-43$

26. Wermers R. Mutual fund herding and the impact on stock prices. Journal of Finance, 1999, 54(2): 581-622

27. Choi N, Skiba H. Institutional herding in international markets. Journal of Banking \& Finance, 2015, 55: 246-259

28. Hessary Y K, Hadzikadic M. An agent-based study of herding relationships with financial markets phenomena. In: 2017 Winter Simulation Conference (WSC), Las Vegas, USA, 2017, 1204-1215

29. Lux T. Herd behaviour, bubbles and crashes. Economic Journal (London), 1995, 105(431): 881-896

30. Kaizoji T. Speculative bubbles and crashes in stock markets: an interacting-agent model of speculative activity. Physica A, 2000, 287(3-4): 493-506

31. Foroni I, Agliari A. Complex price dynamics in a financial market with imitation. Computational Economics, 2008, 32(1-2): 21-36

32. Manahov V, Hudson R. Herd behaviour experimental testing in laboratory artificial stock market settings. Behavioural foundations of stylised facts of financial returns. Physica A, 2013, 392(19): 4351-4372

33. Leece R D, White T P. The effects of firms' information environment on analysts' herding behavior. Review of Quantitative Finance and Accounting, 2017, 48(2): 503-525

34. Avery C, Zemsky P. Multidimensional uncertainty and herd 
behavior in financial markets. American Economic Review, 1998, 88(4): 724-748

35. Carro A, Toral R, San Miguel M. Markets, herding and response to external information. PLoS One, 2015, 10(7): e0133287

36. Galariotis E C, Rong W, Spyrou S I. Herding on fundamental information: a comparative study. Journal of Banking \& Finance, 2015, 50: 589-598

37. Yang W R. Herding with costly information and signal extraction. International Review of Economics \& Finance, 2011, 20(4): 624632

38. Chiarella C. The dynamics of speculative behaviour. Annals of Operations Research, 1992, 37(1): 101-123

39. Iihara Y, Kato H K, Tokunaga T. Investors' herding on the Tokyo stock exchange. International Review of Finance, 2001, 2(1-2): 7198

40. Lakonishok J, Shleifer A, Vishny R W. The impact of institutional trading on stock prices. Journal of Financial Economics, 1992, 32 (1): $23-43$

41. Lux $T$, Marchesi M. Volatility clustering in financial markets: a microsimulation of interacting agents. International Journal of Theoretical and Applied Finance, 2000, 3(04): 675-702

42. Hommes $\mathrm{C} \mathrm{H}$. Heterogeneous agent models in economics and finance. In: Handbook of Computational Economics, 2006, 2: 11091186

43. Chiarella C, Dieci R, Gardini L, et al. A model of financial market dynamics with heterogeneous beliefs and state-dependent confidence. Computational Economics, 2008, 32(1-2): 55-72

44. Peng C, Wang C. Positive feedback trading and stock prices: evidence from mutual funds. 2019, available at the website of ssrn

45. Simon H A. Bounded rationality and organizational learning. Organization Science, 1991, 2(1): 125-134

46. Sciubba E. Bounded rationality. Adaptive Toolbox, 2003, 113(485): F189-F190

47. Morita S. Six susceptible-infected-susceptible models on scale-free networks. Scientific Reports, 2016, 6(1): 1-8

48. Barabási A L. Scale-free networks: a decade and beyond. Science, 2009, 325(5939): 412-413

49. Grimm V, Berger U, Bastiansen F, et al. A standard protocol for describing individual-based and agent-based models. Ecological Modelling, 2006, 198(1-2): 115-126

50. Grimm V, Railsback S F, Vincenot C E, et al. The ODD protocol for describing agent-based and other simulation models: a second update to improve clarity, replication, and structural realism. Journal of Artificial Societies and Social Simulation, 2020, 23(2): 7

51. Francès G, Rubio-Campillo X, Lancelotti C, et al. Decision making in agent-based models. In: European Conference on Multi-Agent Systems. Springer, Cham, 2014, 370-378

52. Lui Y H, Mole D. The use of fundamental and technical analyses by foreign exchange dealers: Hong Kong evidence. Journal of International Money and Finance, 1998, 17(3): 535-545

53. Menkhoff L, Taylor M P. The obstinate passion of foreign exchange professionals: technical analysis. Journal of Economic Literature, 2007, 45(4): 936-972

54. Wang Z, Pan C. Research on the evolution of information strategy and herd behavior based on dynamic scale-free network. Chinese Journal of Management Science, 2018, 26(12): 66-77

55. Lincoln J R, Wellman B, Berkowitz S D. Social structures: a network approach. Administrative Science Quarterly, 1990, 35 (4):746

56. Agnolucci P. The effect of financial constraints, technological progress and long-term contracts on tradable green certificates. Energy Policy, 2007, 35(6): 3347-3359

57. Darmani A, Rickne A, Hidalgo A, et al. When outcomes are the reflection of the analysis criteria: a review of the tradable green certificate assessments. Renewable \& Sustainable Energy Reviews, 2016, 62: 372-381

58. Zuo Y, Zhao X G, Zhang Y Z, et al. From feed-in tariff to renewable portfolio standards: an evolutionary game theory perspective. Journal of Cleaner Production, 2019, 213: 1274-1289

59. National Bureau of Statistics and National Development and Reform Commission. China Energy Statistics Yearbook 2018. Beijing: China Statistics Press, 2019

60. Fagiolo G, Moneta A, Windrum P. A critical guide to empirical validation of agent-based models in economics: methodologies, procedures, and open problems. Computational Economics, 2007, 30(3): 195-226

61. Farmer J D, Joshi S. The price dynamics of common trading strategies. Journal of Economic Behavior \& Organization, 2002, 49 (2): 149-171

62. Schaeffer G J, Boots M G, Mitchell C, et al. Options for design of tradable green certificate systems. Petten, The Netherlands: ECN, 2000 